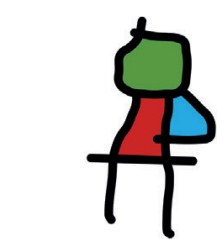

SEICAIP

\section{Allergologia et immunopathologia}

Sociedad Española de Inmunología Clínica, Alergología y Asma Pediátrica

www.all-imm.com

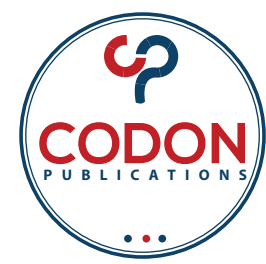

ORIGINAL ARTICLE

\title{
Relationship between montelukast and behavioral problems in preschool children with asthma
}

\author{
Eda Özata ${ }^{a}$, Zülfikar Akelma ${ }^{\mathrm{b}, c *}$, Sacit Günbey ${ }^{\mathrm{a}, \mathrm{d}}$ \\ ${ }^{a}$ Department of Pediatrics, Kecioren Teaching and Research Hospital, Ankara, Turkey \\ ${ }^{b}$ Department of Pediatric Allergy and Immunology, Ankara Kecioren Teaching and Research Hospital, Ankara, Turkey \\ 'Department of Pediatric Allergy and Immunology, Ankara Yıldırım Beyazıt University, Ankara, Turkey \\ ${ }^{d}$ Department of Pediatrics, Ankara Yıldırım Beyazıt University, Ankara, Turkey
}

Received 3 March 2021; Accepted 25 November 2021

Available online 1 January 2022

\section{KEYWORDS \\ Preschool children; \\ Asthma; \\ Montelukast; \\ Check Behavior \\ Checklist; \\ Behavior Problems}

\begin{abstract}
Background: There is insufficient clarity regarding whether or not drugs used in asthma cause behavioral problems in children.

Methods: A total of 155 individuals, categorized into an asthma group $(n=95)$ and a control group $(n=60)$, were enrolled in the current prospective controlled study. The asthma group consisted of patients receiving treatment (inhaled corticosteroids [ICS] or montelukast) for at least 1 month. Check Behavior Checklist (CBCL) for ages 1.5-5 scores for the asthma and controls were compared. The asthma group was divided into two subgroups based on prophylactic therapy received, ICS and montelukast, and these groups' CBCL scores were also compared.

Results: The asthma group consisted of 95 children (ICS subgroup 45, montelukast subgroup 50 ) and the healthy control group of 60 cases. The mean total CBCL score was higher in the asthma group than in the control group ( $42 \mathrm{vs} 32$, respectively, $\mathrm{P}=0.001$ ). Internalization and externalization scores were also higher in the asthma group compared to the control group ( $P=0.004$ and $P=0.005$, respectively). No significant difference was determined in terms of CBCL scores between the ICS and montelukast groups $(P=0.3)$. Montelukast was discontinued in one asthmatic child due to hallucination.

Conclusion: This study determined a higher rate of behavioral problems in preschool children with asthma compared to healthy children. In contrast to other studies in the literature, we determined no difference in terms of total $\mathrm{CBCL}$, and internalization and externalization scores of children with asthma who received ICS and montelukast. Nevertheless, it should be kept in mind that montelukast may cause serious neuropsychiatric events such as hallucination.

(c) 2022 Codon Publications. Published by Codon Publications.
\end{abstract}

*Corresponding author: Zülfikar Akelma. Department of Pediatric Allergy and Immunology, Ankara Yıldırım Beyazıt University, Babür Caddesi No:44 (06080) Altındağ, Ankara, Turkey. Email address: akelma@gmail.com 


\section{Introduction}

Asthma is a chronic inflammatory airway disease resulting in episodic airway obstruction leading to mortality. It affects approximately 358 million individuals worldwide. The prevalence ranges from 1 to $22 \%$, depending on the country involved, and it is the most frequently seen chronic disease in childhood. In addition to acute and longterm pulmonary complications, asthma can also adversely affect physical, cognitive, and psychological development in childhood. ${ }^{1}$ Higher rates of internalizing disorders, such as anxiety and mood disorders, and externalizing disorders, such as attention deficit and hyperactivity, have been found in asthmatic children compared to healthy individuals. Behavioral disorders are also more frequent, particularly in severe asthma cases. ${ }^{2,3}$ Behavioral problems in asthmatic children are thought to be predominantly associated with symptoms such as cough, wheezing, and respiratory difficulty.

Montelukast, a leukotriene receptor antagonist, is recommended for symptom control and long-term treatment in preschool children with asthma and in the treatment of allergic rhinitis. ${ }^{4}$ Montelukast is also frequently used in preschool children in daily practice. High rates of anxiety, aggression, nightmares, and sleep disorder have been reported in children using montelukast in retrospective analysis of pharmacovigilance studies. ${ }^{5,6}$ The prescription of montelukast has also been linked to the emergence of neuropsychiatric findings in wide patient groups. ${ }^{7,8}$ However, retrospective analysis of the Merck clinical trial data showed that behavior-related adverse experiences and suicide were rare in people who use montelukast, with rates similar to those of placebo.9,10 There is still insufficient information in the literature concerning whether montelukast use in asthma and the treatment thereof caused behavioral problems, and if it does, what these problems may be.

The purpose of the this prospective controlled study was to investigate the development of behavioral changes (irritability, night terror, sleep disorders, anxiety, etc.) in children aged 1.5-5 years using montelukast, and if these did occur, the relationship with asthma and accompanying risk factors.

\section{Materials and methods}

The parents of children aged $1.5-5$ years presenting to the Health Sciences University, Ankara Kecioren Teaching and Research Hospital, Pediatric Allergy and Immunology Outpatient Clinic and Healthy Child Outpatient Clinic, Turkey, between November 2017 and June 2018, were simultaneously invited to participate in the study.

Children presenting to the Pediatric Allergy and Immunology Clinic due to recurrent cough, wheezing and shortness of breath, and diagnosed with asthma based on the Global Initiative for Asthma (GINA) guideline constituted the asthma group. ${ }^{11}$ Asthma diagnosis and treatment were performed by a specialist physician independently of the study (Z.A.). The study forms and behavior evaluation scale were assessed by a different physician during clinical controls (E.Ö.). Children presenting to the Healthy Child
Clinic for routine health checks and with no health problems constituted the control group.

Patients diagnosed with asthma based on the GINA guideline were started on inhaled corticosteroid (ICS) or montelukast as a prophylactic therapy. Patients were placed under regular follow-up by the Pediatric Allergy and Immunology Clinic. Demographic and clinical information for the study population were recorded onto case report forms. The asthma group was divided into ICS and montelukast subgroups, depending on the prophylactic therapy received. All children with asthma who agreed to participate in the study were administered the Check Behavior Checklist (CBCL) for ages 1.5-5 at the end of the first month of treatment at the earliest.

The study was completed with 155 children aged 1.5-5 years, 95 in the asthma group and 60 in the healthy control group (Figure 1). Montelukast therapy was stopped in one case due to developing hallucinations on the 15th day of treatment, and that patient was excluded from the study. Information such as socioeconomic levels, sex, weight-height, age of the child, number of siblings, type and duration of delivery, breastfeeding and transition to supplementary food, history of atopy, family history of allergy and allergen sensitivity, presence of allergens at home, severity of asthma, and drugs used and durations thereof for the asthma group were recorded onto specially prepared case report forms.

Inclusion criteria for the asthma group were being under follow-up with diagnosis of asthma based on the GINA guideline and using montelukast or ICS as prophylactic therapy. Children with chronic disease other than asthma, with psychiatric disease and a history of regular medication use, with illiterate parents, speaking languages other than Turkish and failing to attend follow-ups, not fully completing the CBCL scale, or with attention-deficit hyperactivity disorder and other psychiatric disorders were excluded from the study.

Complete blood count and total serum total immunoglobulin $E$ (IgE) tests were performed at laboratory investigation. Complete blood count was performed on a hematological autoanalyzer (Cell-Dyne 4000, Abbott). Serum total IgE was measured using the "chemiluminescence" method and automatic immunoassay (Beckman Coulter, Fullerton, CA) and was expressed as $\mathrm{IU} / \mathrm{mL}$.

Atopic sensitivity in the asthma group was assessed using skin prick tests. Histamine as a positive control, saline as a negative control, and the allergen to be tested were applied at $2 \mathrm{~cm}$ intervals on the forearm. The formation of induration $3 \mathrm{~mm}$ or greater in size in the hyperemic area was regarded as positive.

The CBCL developed in 2000 by Achenbach and Rescorla is an updated version of the Child Behavior Checklist for ages 2-3 developed by Achenbach in 1992. It contains 99 items and three open-ended additional questions involving demographic data for the child and the family and the child's behavioral and emotional problems in the previous 2 months. It is used to determine the behavioral and emotional problems of children aged 1.5-5 years and is completed by parents or guardians. The family answers the questions from the options 0 - not true (to the best of your knowledge), 1 - sometimes or slightly true, or 2 - very often or often true. The CBCL contains two broad 


\section{Study Population}

Children with asthma and healthy controls aged 18-60 months were invited to participate in the study.

\section{Asthma Group}

Children with mild persistent asthma, aged 18-60 months, were included in the study and placed under follow-up.

Asthma Group $(\mathrm{n}=95)$
A behavioral evaluation scale was
applied to the parents of children
using ICS or montelukast daily for least
1 month $(n=95)$.

\section{Asthma Group \\ ICS subgroup $(n=45)$}

Montelukast subgroup $(n=50)$

Figure 1 Study population flow chart.

ICS: Inhaled corticosteroid.

bands involving internalizing and externalizing scores, and seven narrow bands involving emotional reactivity, anxiety or depression, somatic complaints, withdrawal or depression, attention problems, aggressive behaviors, and sleep problems. Separate internalizing (emotional reactivity, withdrawal or depression, somatic complaints, and anxiety or depression), externalizing (attention problems and aggressive behaviors), sleep problems, and other problems are elicited. It also permits the evaluation of mood problems, anxiety, generalized developmental problems, attention-deficit or hyperactivity problems, and oppositional defiance disorder problems in terms of fields determined based on DSM IV-TR diagnostic criteria. The validity and reliability of the scale for Turkish children were confirmed by Prof. Dr. Neșe Erol in 2003. The CBCL was administered to parents of asthma and control groups during routine clinical assessments. ${ }^{12}$

Ethical approval for the study was granted by the Health Sciences University, Ankara Kecioren Teaching and Research Hospital Ethical Committee (No. 2012-KAEK-15/1523, dated $11 / 10 / 2017)$. The study commenced once informed consent had been obtained from children's parents.

Statistical analysis was performed on Statistical Package for Social Sciences (SPSS) for Windows version 21.0 software. Data distribution was evaluated using the Kolmogorov-Smirnov test. Data were normally distributed when $\mathrm{P}>0.05$. Normally distributed data were expressed as mean \pm standard deviation, and abnormally distributed data as median values (interquartile range). The Mann-Whitney $U$ test was applied in the comparison of continuous variables between the groups, and the chi-square test in the comparison of categorical data. Categorical data were expressed as number and percentage. Spearman's test was used for correlation analyses between laboratory data and scale scores. $\mathrm{P}$ values less than 0.05 were regarded as statistically significant.

\section{Results}

This study was completed with 155 cases. The asthma group consisted of 95 children (45 in the ICS group and 50 in the montelukast group), and the healthy control group consisted of 60 cases. The study group's sociodemographic characteristics are shown in Table 1.

The asthma and control groups' CBCL results were compared. The mean total CBCL score of the asthma group was higher than that of the control group (42 and 32, respectively; $\mathrm{P}=0.001$ ). Internalization and externalization scores were also higher in the asthma group than in the control group ( $P=0.004$, and $P=0.005$, respectively). The subgroups comprising the internalization and externalization scores were then examined. Accordingly, emotional reactivity, anxious or depressed, somatic complaints, and withdrawal scores were compared between the asthma and control groups. All these scores, except for somatic complaints, were higher in the asthmatic children. Aggressive behavior scores were higher in the asthma group, but attention problems were similar in the two groups. Sleep and other problems scores were also higher in the asthmatic group. CBCL scores are shown in Table 2.

The asthma group was also analyzed in terms of treatments received. Allergic evaluation of children receiving ICS and montelukast is shown in Table 3. The two subgroups were similar in terms of family history of allergic disease, history of atopic disease, environmental factors, frequency of asthma attacks, atopic sensitivity, serum total IgE level, and eosinophil count $(P>0.05)$.

According to duration of treatment, the majority of patients in the asthma group had received treatment for 1 month. Forty of the patients using ICS received budesonide, and five received fluticasone propionate. There was no difference between the groups according to asthma severity, with mild persistent asthma being determined in 
Table 1 Sociodemographic characteristics of the study population.

\begin{tabular}{|c|c|c|c|}
\hline & Asthma group $(\mathrm{n}=95)$ & Control group $(n=60)$ & $P$ \\
\hline Age, month Median (IQR) & $38(26-51)$ & $33.5(25.25-47.25)$ & 0.30 \\
\hline Sex, n (\%) & & & 0.39 \\
\hline Male & $61(64.2)$ & $34(56.7)$ & \\
\hline Female & $34(35.8)$ & $26(43.3)$ & \\
\hline Height (cm), Median (IQR) & $98(90-110)$ & $92(85-102)$ & 0.003 \\
\hline Weight (kg), Median (IQR) & $15(13-18)$ & $14(11,5-16)$ & 0.038 \\
\hline BMI $\left(\mathrm{kg} / \mathrm{m}^{2}\right)$, Median (IQR) & $15.3(14.40-16.28)$ & $16(14.71-17.34)$ & 0.012 \\
\hline Delivery, n (\%) & & & 0.60 \\
\hline Vaginal & $36(60)$ & $53(55.8)$ & \\
\hline Cesarean & $42(44.2)$ & $24(40.0)$ & \\
\hline Prematurity, n (\%) & $16(16.8)$ & $6(10.0)$ & 0.23 \\
\hline Breastfeeding, n (\%) & $92(96.8)$ & $59(98.3)$ & 0.56 \\
\hline $\begin{array}{l}\text { Duration of breastfeeding, } \\
\text { (median [min-max]) }\end{array}$ & $15(6-22)$ & $15(12-20)$ & 0.49 \\
\hline Formula, n (\%) & $55(58.5)$ & $23(38.3)$ & 0.015 \\
\hline $\begin{array}{l}\text { Supplementary food time, } \\
\text { months (mean } \pm S D \text { ) }\end{array}$ & $6(5-6)$ & $5(5-6)$ & 0.43 \\
\hline Attending kindergarten, $\mathrm{n}(\%)$ & $27(28.4)$ & $9(15.0)$ & 0.054 \\
\hline Consanguinity, n (\%) & $12(12.6)$ & $5(8.6)$ & 0.44 \\
\hline Father's age, years & $34(30-37.5)$ & $33(29-38)$ & 0.13 \\
\hline Mother's age, years & $30(27-33)$ & $30(26.25-34.75)$ & 0.53 \\
\hline
\end{tabular}

BMI: Body mass index; IQR: Interquartile range

Table 2 Comparison of asthma and control group CBCL scores.

\begin{tabular}{lclc}
\hline & $\begin{array}{c}\text { Asthma } \\
\text { group }(\mathrm{n}=95)\end{array}$ & $\begin{array}{c}\text { Control group } \\
(\mathrm{n}=60)\end{array}$ & $\mathrm{P}$ \\
\hline Total score & $42(28-55)$ & $32(21.25-40)$ & 0.001 \\
Internalization score & $13(9-20)$ & $10(5-15)$ & 0.004 \\
Externalization score & $13(7-19)$ & $10(5-13)$ & 0.005 \\
Emotional reactivity & $3(2-5)$ & $2(1-3.75)$ & 0.003 \\
Anxious or depressed & $4(3-6)$ & $3(2-5)$ & 0.016 \\
Somatic complaints & $3(2-5)$ & $2(1-4)$ & 0.127 \\
Withdrawn & $2(1-4)$ & $1(0-2.75)$ & 0.018 \\
Aggressive behavior & $10(5-15)$ & $7(4-11)$ & 0.003 \\
Attention problems & $3(2-4)$ & $2(1-3.75)$ & 0.107 \\
Sleep problems & $3(2-6)$ & $3(1-4)$ & 0.040 \\
Other problems & $11(8-15)$ & $9(6-11.75)$ & 0.003 \\
\hline CBCL: Child Behavior Checklist & &
\end{tabular}

CBCL: Child Behavior Checklist

Data expressed as median (interquartile range [IQR]) values; higher scores indicate greater behavioral problems.

all patients (Table 4). No statistically significant difference was also observed between the groups in terms of duration of drug use $(\mathrm{P}>0.05)$. Asthma group $C B C L$ scores according to treatments received are shown in Table 5. All scores were similar between the subgroups receiving ICS and montelukast. No variation was also observed in $\mathrm{CBCL}$ scores based on gender or the family's economic status (data not shown).

\section{Discussion}

Total CBCL scores in this prospective controlled study were higher in preschool children with asthma than in the control group. Internalization and externalization behavior scores were also higher in the asthmatic children than in the controls. Sleep problem and other behavioral problem scores were also higher in the children with asthma. These findings show that preschool children with asthma are more disposed to behavioral problems, irrespective of the cause.

A meta-analysis reported increased internalization disorders such as anxiety disorder and depression, and externalization disorders such as lack of attention, hyperactivity, and aggressive behavior in asthmatic children aged 4-19 compared to healthy children. Internalization problems were greater than externalization disorders. At the same time, behavioral problems were correlated with the severity of asthma, being greater in severe cases. ${ }^{3}$ The National Health Interview Survey (NHIS) from the USA investigated accompanying comorbid diseases in asthmatic children and reported increased behavioral disorders such as depression, and mood, concentration, anxiety, and neurotic disorders in asthmatic children compared to nonasthmatics. ${ }^{13}$ The study was performed using database findings. Similarly, a close correlation has been revealed between asthma and anxiety. ${ }^{14,15}$

The nature of the relationship between asthma and behavioral problems, the reason why such problems are more prevalent in asthmatic children than in healthy peers, and whether they are associated with ICS and montelukast are still unclear. Asthma is a disease that commences in the preschool period, which is capable of progressing, and involves a risk of mortality due to asphyxia. It causes anxiety in both the child and the family. The behavioral problems seen in asthmatic children may be explained in terms of different causes. The principal stress factors are the responsibility required in terms of adhering to treatment, the need to avoid asthma triggers, and the asthma attacks that occur. The need to present to the emergency department during 
Table 3 Familial allergic disease and exposure to allergens in children with asthma.

\begin{tabular}{|c|c|c|c|}
\hline & ICS group $(n=45)$ & Montelukast group $(n=50)$ & $P$ \\
\hline \multicolumn{4}{|l|}{ Parental history of allergic disease, n (\%) } \\
\hline Asthma & $6(13.6)$ & $14(28)$ & 0.8 \\
\hline Atopic dermatitis & $0(0)$ & $4(8)$ & 0.1 \\
\hline Allergic rhinitis & $2(4.5)$ & $3(6)$ & 0.9 \\
\hline Exposure to smoking, $\mathrm{n}(\%)$ & $27(60)$ & $31(62)$ & 0.8 \\
\hline Pets, n (\%) & $6(13.3)$ & $3(6)$ & 0.3 \\
\hline \multicolumn{4}{|l|}{ History of allergic disease, $\mathrm{n}(\%)$} \\
\hline Atopic dermatitis & $1(2)$ & $1(2)$ & 0.8 \\
\hline Allergic rhinitis & $1(2)$ & $2(4)$ & \\
\hline Food allergy & $0(0)$ & $1(2)$ & \\
\hline Skin prick test positivity, n (\%) & $9(20)$ & $6(12)$ & 0.2 \\
\hline Total IgE, IU/mL, n (\%) (median [min-max]) & $23.4(1-324)$ & $21(1.5-188)$ & 0.6 \\
\hline Total eosinophil count, $\mathrm{n}(\%)$ (median [min-max]) & $196(3-1300)$ & $160(2-1210)$ & 0.7 \\
\hline Number of attacks in the previous 3 months (median [min-max]) & $2(0-7)$ & $2(0-5)$ & 0.6 \\
\hline Number of attacks in the previous 6 months (median [min-max]) & $2(0-7)$ & $3(0-7)$ & 0.5 \\
\hline Number of attacks in the previous 12 months (median [min-max]) & $3(0-8)$ & $4(0-8)$ & 0.6 \\
\hline $\begin{array}{l}\text { Number of admissions to hospital or hospitalizations in the } \\
\text { previous } 12 \text { months, } \mathrm{n}(\%)\end{array}$ & & & 0.5 \\
\hline None & $3(6.6)$ & $1(2)$ & \\
\hline One & $4(8.9)$ & $5(10)$ & \\
\hline Two & $8(17.8)$ & $6(12)$ & \\
\hline Three or more & $30(66.7)$ & $38(76)$ & \\
\hline
\end{tabular}

ICS: Inhaled corticosteroid

Table 4 Treatments and durations thereof among patients receiving maintenance therapy.

\begin{tabular}{lcccc}
\hline & \multicolumn{4}{c}{ Duration } \\
\cline { 2 - 5 } Treatment & 1 month & 2 months & $3-6$ months & $\geq 6$ months \\
\hline Inhaled corticosteroid, $\mathrm{n}(\%)$ & $27(60)$ & $1(2.2)$ & $10(22.2)$ & $7(15.6)$ \\
Montelukast, $\mathrm{n}(\%)$ & $28(56)$ & $7(14)$ & $6(12)$ & 9.1 \\
\hline
\end{tabular}

Table 5 Comparison of asthma group total CBCL and internalization and externalization scores according to treatment received.

\begin{tabular}{lccc}
\hline & $\begin{array}{c}\text { ICS group } \\
(\mathrm{n}=45)\end{array}$ & $\begin{array}{c}\text { Montelukast } \\
\text { group }(\mathrm{n}=50)\end{array}$ & $\mathrm{P}$ \\
\hline Total score & $40(27-52.5)$ & $42.5(29-61.5)$ & 0.34 \\
Internalization score & $13(8-18)$ & $12.5(9.75-21.5)$ & 0.41 \\
Externalization score & $13(7-17.5)$ & $12.5(7-20.25)$ & 0.40 \\
Emotional reactivity & $3(2-4)$ & $4(2-6)$ & 0.13 \\
Anxious or depressed & $5(2-6)$ & $4(3-6.25)$ & 0.8 \\
Somatic complaints & $3(1-4)$ & $3(2-5)$ & 0.17 \\
Withdrawn & $2(0-4)$ & $2(1-4)$ & 0.76 \\
Aggressive behavior & $10(4.5-14)$ & $10.5(5.75-16)$ & 0.53 \\
Attention problems & $3(1.5-4)$ & $3(2-5)$ & 0.13 \\
Sleep problems & $3(2-5)$ & $3.5(2-6)$ & 0.60 \\
Other problems & $11(8-18)$ & $10.5(6.75-16.25)$ & 0.92 \\
\hline CBCL: Child Behavior Che
\end{tabular}

CBCL: Child Behavior Checklist; ICS: Inhaled corticosteroid Data expressed as median (interquartile range [IQR]) values; higher scores indicate greater behavioral problems. asthma attacks, interruption of daily life due to hospitalizations, and time spent away from home all exacerbate the existing stress. The effect of these factors on social life increases in line with the severity of the asthma, and it is thought that behavioral problems can emerge as a result. ${ }^{16}$

The current prospective controlled study examined the association between the high CBCL scores determined in preschool children with asthma and the drugs used in treatment. We determined no difference between the groups receiving ICS and montelukast prophylactic therapy in terms of total $\mathrm{CBCL}$, internalization, or externalization scores. The $\mathrm{CBCL}$ subgroup analysis also revealed no difference between the groups in terms of sleep and other problems. In the light of these findings, we concluded that greater behavioral problems were observed in children with asthma compared to healthy children. This study also revealed no montelukast use-related increase in CBCL scores.

Quak et al. ${ }^{17}$ reported that ICS used in maintenance treatment of children with asthma did not increase behavioral problems. Several studies have investigated the relationship between montelukast use and behavioral problems. The consensus is that montelukast use is closely associated with behavioral problems. In 2009, the US Food and Drug Administration (FDA) issued a label warning for 
montelukast concerning neuropsychiatric events. Warnings were also included in the prescription leaflet in post marketing. Neuropsychiatric events continue to be reported for montelukast. ${ }^{18}$

In a recent study, Glockler-Lauf et al. ${ }^{8}$ examined the presentations to hospital due to behavioral problems among children aged 5-18 who were prescribed maintenance asthma medications in 2004-2015. Eight hundred ninety-eight neuropsychiatric events were determined. The rate of such events was 1.9 times higher in children previously prescribed montelukast. The study was based on patient record systems and supports the idea that neuropsychiatric events are concentrated in children using montelukast.

In a nested case-cohort study, Benard et al. ${ }^{7}$ investigated cases in which medication was stopped due to neuropsychiatric side effects in asthmatic children started on montelukast. They found that the drug was discontinued due to neuropsychiatric side effects in 16 out of 106 asthmatic children started on montelukast. These side effects generally developed within 2 weeks of the drug being started. A higher rate of drug discontinuation due to side effects was observed in children using montelukast compared to asthmatic children using ICS.

The current prospective controlled study observed higher total $\mathrm{CBCL}$ scores in preschool children with asthma compared to healthy controls. However, asthmatic children continued to use ICS or montelukast, and the subsequent increase in behavioral scores did not result in pathology. We determined no variation in $\mathrm{CBCL}$ scores between asthmatic children using ICS or montelukast, and drug use did not therefore produce an increase in $\mathrm{CBCL}$ scores. However, medication was discontinued in one asthmatic child due to developing hallucination 15 days after being started on montelukast. That patient was excluded from the study due to not meeting the inclusion criteria. We encountered no findings that montelukast results in a general increase in neuropsychiatric side effects. However, side effects may emerge incidentally in some patients. The parents of children started on montelukast must therefore be appropriately informed, and patients must be monitored in terms of potential side effects.

In conclusion, the present study determined a higher rate of behavioral problems in patients under follow-up due to asthma compared to healthy children. In contrast to previous studies, we determined no difference in total $\mathrm{CBCL}$, and internalization or externalization scores between children receiving ICS and montelukast. Even so, care is required in terms of neuropsychiatric problems at the beginning of treatment in preschool children started on montelukast, as montelukast was discontinued in an asthmatic child due to hallucination. However, it should be kept in mind that montelukast may cause serious neuropsychiatric events such as hallucinations.

\section{Conflict of interest}

All authors declare that they have no conflicts of interest relevant to this article to disclose. They do not have any financial relationship with the organization that sponsored the research.

\section{References}

1. Soriano JB, Abajobir AA, Abate $\mathrm{KH}$, Abera SF, Agarwal A, Ahmed MB, et al. Global, regional, and national deaths, prevalence, disability-adjusted life years, and years lived with disability for chronic obstructive pulmonary disease and asthma, 1990-2015: A systematic analysis for the Global Burden of Disease Study 2015. Lancet Respir Med. 2017;5(9):691-706. https://doi.org/10.1016/S2213-2600(17)30293-X

2. Calam R, Gregg L, Simpson B, Morris J, Woodcock A, Custovic A. Childhood asthma, behavior problems, and family functioning. J Allergy Clin Immunol. 2003;112(3):499-504. https://doi.org/10.1016/S0091-6749(03)01606-3

3. McQuaid EL, Kopel SJ, Nassau JH. Behavioral adjustment in children with asthma: A meta-analysis. J Dev Behav Pediatr. 2001;22(6):430-9. https://doi.org/10.1097/00004703200112000-00011

4. Scadding GK, Kariyawasam HH, Scadding G, Mirakian R, Buckley RJ, Dixon T, et al. BSACl guideline for the diagnosis and management of allergic and non-allergic rhinitis (Revised Edition 2017; First edition 2007). Clin Exp Allergy. 2017;47(7):856-89. https://doi.org/10.1111/cea.12953

5. Aldea Perona A, García-Sáiz M, Sanz Álvarez E. Psychiatric disorders and montelukast in children: A disproportionality analysis of the VigiBase ${ }^{\circledR}$. Drug Saf. 2016;39(1):69-78. https://doi. org/10.1007/s40264-015-0360-2

6. Haarman MG, van Hunsel F, de Vries TW. Adverse drug reactions of montelukast in children and adults. Pharmacol Res Perspect. 2017;5(5):e00341. https://doi.org/10.1002/prp2.341

7. Benard B, Bastien V, Vinet B, Yang R, Krajinovic $M$, Ducharme FM. Neuropsychiatric adverse drug reactions in children initiated on montelukast in real-life practice. Eur Respir J. 2017;50(2):1700148. https://doi.org/10.1183/13993003.001482017

8. Glockler-Lauf SD, Finkelstein Y, Zhu J, Feldman LY, To T. Montelukast and neuropsychiatric events in children with asthma: A nested case-control study. J Pediatr. 2019;209:17682.e4. https://doi.org/10.1016/j.jpeds.2019.02.009

9. Philip G, Hustad CM, Malice MP, Noonan G, Ezekowitz A, Reiss TF, et al. Analysis of behavior-related adverse experiences in clinical trials of montelukast. J Allergy Clin Immunol. 2009;124(4):699-706.e8. https://doi.org/10.1016/j. jaci.2009.08.011

10. Philip G, Hustad C, Noonan G, Malice MP, Ezekowitz A, Reiss TF, et al. Reports of suicidality in clinical trials of montelukast. J Allergy Clin Immunol. 2009;124(4):691-6.e6. https://doi.org/10.1016/j.jaci.2009.08.010

11. Global Initiative for Asthma (GINA). Global strategy for asthma management and prevention. Søren Pedersen $M$, Helen $K$ Reddel, MBBS PhD, Editor; 2017.

12. Achenbach TM, Rescorla LA. Manual for the ASEBA preschool forms and profiles: An integrated system of multi-informant assessment. Burlington, VT: University of Vermont Department of Psychiatry; 2000.

13. Mirabelli MC, Hsu J, Gower WA. Comorbidities of asthma in U.S. children. Respir Med. 2016;116:34-40. https://doi. org/10.1016/j.rmed.2016.05.008

14. Del Giacco SR, Cappai A, Gambula L, Cabras S, Perra S, Manconi PE, et al. The asthma-anxiety connection. Respir Med. 2016;120:44-53. https://doi.org/10.1016/j.rmed.2016.09.014

15. Vila G, Nollet-Clemençon C, De Blic J, Mouren-Simeoni MC, Scheinmann P. Prevalence of DSM IV anxiety and affective disorders in a pediatric population of asthmatic children and adolescents. J Affect Disord. 2000;58(3):223-31. https://doi. org/10.1016/S0165-0327(99)00110-X

16. Booster GD, Oland AA, Bender BG. Psychosocial factors in severe pediatric asthma. Immunol Allergy Clin North Am. 2016;36(3):449-60. https://doi.org/10.1016/j.iac.2016.03.012 
17. Quak W, Klok T, Kaptein AA, Duiverman EJ, Brand PLP. Preschool children with high adherence to inhaled corticosteroids for asthma do not show behavioural problems. Acta Paediatr Int J Paediatr. 2012;101(11):1156-60. https://doi.org/10.1111/ j.1651-2227.2012.02805.x

18. US Food and Drug Administration. Updated information on leukotriene inhibitors: Montelukast (marketed as Singulair),
Zafirlukast (marketed as Accolate) and Z (marketed as Z and ZC. U.S. Food and Drug Administration. Available from: https:// wayback.archive-it.org/7993/20170111080414/http://www. fda.gov/Drugs/DrugSafety/PostmarketDrugSafetyInformation forPatientsandProviders/DrugSafetyInformationforHeath careProfessionals/ucm165489.htm. https://doi.org/10.1201/ b19633 